\title{
The Social Context of Racial Boundary Negotiations: Segregation, Hate Crime, and Hispanic Racial Identification in Metropolitan America
}

\author{
Michael T. Light, ${ }^{a}$ John Iceland ${ }^{\mathrm{b}}$
}

a) Purdue University; b) Pennsylvania State University

Abstract: How the influx of Hispanics is reshaping the U.S. racial landscape is a paramount question in sociology. While previous research has noted the significant differences in Hispanics' racial identifications from place to place, there are comparatively few empirical investigations explaining these contextual differences. We attempt to fill this gap by arguing that residential context sets the stage for racial boundary negotiations and that certain environments heighten the salience of inter-group boundaries. We test this argument by examining whether Hispanics who live in highly segregated areas and areas that experience greater levels of anti-Hispanic prejudice are more likely to opt out of the U.S. racial order by choosing the "other race" category in surveys. Using data from the American Community Survey and information on anti-Hispanic hate crimes from the FBI, we find support for these hypotheses. These findings widen the theoretical scope of the roles segregation and prejudice play in negotiating racial identifications, and have implications for the extent to which Hispanics may redefine the U.S. racial order.

Keywords: racial/ethnic boundaries; segregation; hate crimes

Citation: Michael T. Light and John Iceland. 2016. "The Social Context of Racial Boundary Negotiations: Segregation, Hate Crime, and Hispanic Racial Identification in Metropolitan America". Sociological Science 3: 6184.

Received: October 20, 2015

Accepted: November 28, 2015

Published: February 8, 2016

Editor(s): Jesper Sørensen, Mario Small

DOI: $10.15195 / \mathrm{v} 3 . \mathrm{a} 4$

Copyright: (C) 2016 The Author(s). This open-access article has been published under a Creative Commons Attribution License, which allows unrestricted use, distribution and reproduction, in any form, as long as the original author and source have been credited. (0)(1)
THE unprecedented growth in the Hispanic population over the last half-century has prompted debates about if and how the U.S. color line will be redrawn. While some argue that the influx of Latinos ${ }^{1}$ will ultimately "destroy" the Anglo American racial system (Rodriguez 2007), others argue that the definition of "whiteness" will expand to include lighter-skinned Hispanics, thus keeping the black/white divide intact (Yancey 2003). Others have articulated a third option in which Latinos will represent a new racial group, separate from both blacks and whites (Gomez 2007).

Building on the theoretical perspective that racial and ethnic identities are both socially constructed and continuously negotiated (Barth 1969), researchers have begun to focus on the determinants of Hispanics' racial self-identifications to address the continued relevance of the black/white divide in contemporary U.S. society. However, previous research has focused primarily on how individual-level factors and economic mobility affect Hispanics' racial identifications (Frank et al. 2010; Alba 2009). By comparison, relatively less is known about the role that social context may play in determining how Hispanics view themselves in relation to other groups. This is an important gap in the literature as previous research shows that Hispanics' racial identifications vary significantly from place to place. For example, 52 percent of Hispanics in California identified as "some other race" on the 2000 Census, while only 37 percent in Texas and 17 percent in Florida did (Rumbaut 2009). Yet, while it is clear that racial identifications vary by context, there are few 
empirical investigations explaining these contextual differences. This is somewhat surprising given the primacy of ecological arguments in theoretical accounts of racial/ethnic boundary making and unmaking. According to the emergent ethnicity perspective, ethnic identity develops out of "structural conditions characterizing American cities and the position of groups in American social structure" (Yancey et al. 1976: 391), chief among these conditions is the degree of residential segregation among racial and ethnic groups.

Another view, the reactive ethnicity perspective, maintains that identity is "the product of confrontation with an adverse native mainstream and the rise of defensive identities and solidarities to counter it" (Portes and Rumbaut 2001: 284). However, the research in support of the reactive ethnicity perspective has been limited to either smaller case studies (Jiménez 2010; Massey and Sanchez 2010; Rumbaut 2008) or to personal experiences with prejudice (Golash-Boza and Darity 2008; Michael and Timberlake 2008). As a result, there have been comparatively few systematic empirical investigations into whether living in social contexts marred with inter-group conflict and prejudice affects Hispanics' racial self-identification.

In this study, we use data from the American Community Survey and the FBI Hate Crime reports to test both the emergent ethnicity and reactive ethnicity perspectives by investigating the roles that segregation and anti-Hispanic hate crimes play in determining the racial self-identifications of Hispanics. We argue that social contexts characterized by group-prejudice and segregation heighten the salience of inter-group boundaries, and in such contexts Hispanics will be less likely to identify with one of the existing U.S. racial classifications and instead mark "other race" on questionnaires. The "other race" option is important for understanding the future of U.S. race relations. Between 1960 and 2010 the number of individuals identifying as "other race" increased dramatically, from roughly 200,000 to over 19 million, and today 97 percent of those who mark "other race" are of Hispanic origin. Research suggests this trend represents both a rejection of the current U.S. racial classifications and a "conscious decision about [Hispanics'] racial identification and an assertion of a meaningful label" (Vaquera and Kao 2006: 389; see also Frank et al. 2010; Michael and Timberlake 2008; Rodriguez and Cordero-Guzman 1992). Understanding the determinants of Hispanics' racial identifications, particularly of the "other race" designation, is thus a paramount question for social scientists.

\section{Boundary Making and Unmaking}

Building on the tradition of Barth (1969), and recent extensions by Wimmer (2008), we view racial and ethnic divisions as products of classificatory struggles in which "individuals and groups struggle over who should be allowed to categorize, which categories are to be used, which meanings they should imply and what consequences they should entail" (Wimmer 2007: 11). The primary implication of this boundary construction framework is that categories are contestable and capable of change.

This is especially the case among Hispanics for whom ambiguity about their "racial" identity abounds, including whether the distinction between ethnicity and race captures the actual ways that Hispanics understand group boundaries (Lan- 
dale and Oropesa 2002). Many Latin Americans consider themselves to be a mix of Spanish and Indian ancestry or consider their ethnicity (i.e. country of origin) to be their 'race' (Brown, Hitlin and Elder 2006). Because the U.S. government officially recognizes 'race' and 'ethnicity' as separate and unique constructs (Office of Management and Budget 1997), unlike in Latin American countries of origin (Morning 2008), Hispanics are forced to reconcile and negotiate their 'racial' identification within the existing U.S. racial classification system.

In response to the official race classifications dictated by the state, Hispanics have several options to negotiate their identifications and the social boundaries around them. They could engage in "boundary contraction" wherein they reject the available choices and instead promote other nonracial modes of classification (Kusow 2006). Another option is to engage in "boundary blurring" in which existing racial boundaries are expanded and social distinctions become more fluid. Some researchers interpret the large population of Hispanics who identify as 'white' as evidence of this form of blurring (Alba and Nee 2003). A third option is to reject or challenge the existing racial boundaries. Rather than working within the existing U.S. racial framework, several authors interpret large numbers of Latinos choosing the "other" race category as asserting a distinct Hispanic/Latino racial identification, rejecting the existing categories as well as the distinction between "race" and "ethnicity" (Michael and Timberlake 2008; Vaquera and Kao 2006). In line with this view, Rodriguez (2000) argues that many Hispanics mark "other race" on the census because simple categories of "white" and "black" do not capture the complexity of their identification, which is often comprised of combinations of nationality, culture, socialization, and ethnicity. Similarly, Hitlin et al. (2007) suggest the overlap between racial and ethnic boundaries among Latinos is not the result of conceptual confusion between these categories, but due to the fact that ethnicity or national origins are often the most salient social identities that distinguish in-group from out-group members for many Latinos in the U.S. To the extent that ethnic boundaries are more salient among Hispanics, it follows from this perspective that they will be less likely to identify within the existing racial classification system which treats racial and ethnic identifications separately.

Thus, whether Hispanics will one day be incorporated into the existing racial structure of the U.S., or ultimately redefine it, is largely dependent on the salience of the racial/ethnic boundaries created by both in-group and out-group members. An important question for the existing theoretical accounts of boundary construction, then, is what determines the salience of social boundaries? In this study we seek to extend the sociological literature on race and ethnicity by investigating how both the structural features of community contexts and the actions of out-group members affect racial boundary identifications. We suggest residential context plays a key role in influencing the available options that ultimately shape how actors identify their race, and propose segregation and prejudice as two principle ecological characteristics that likely condition the salience of ethnic/racial boundaries. In this regard, our study aligns with the growing literature which views race as a fluid social construction, one that is created and negotiated in everyday interactions and is subject to change across contexts (Saperstein and Penner 2012). It also attempts to answer recent calls to examine racial formation at different units 
of analysis (Saperstein et al. 2013) by situating individual Hispanics in the broader social contexts within which their racial self-identifications occur.

\section{Segregation and Boundaries}

According to the emergent ethnicity perspective, ethnic identities are formed and crystallized in ethnic residential concentrations, which in turn reinforce the maintenance of kinship and friendship networks around a shared ethnic or group identity (Yancey et al. 1976). There are several mechanisms through which segregated communities may affect the available options for boundary negotiations. First, in segregated ethnic communities there is less opportunity for the day-to-day interactions with out-group members that previous research has highlighted as a key to boundary blurring (Alba and Nee 2003). Second, segregated communities are more likely to develop a wide range of local institutions such as grocery stores, bars, schools and churches based on shared racial/ethnic identification (Fitzpatrick 1966). Third, ethnically segregated communities also influence the demographic make-up of schools and businesses, limiting the diversity of dating pools and thus decreasing the likelihood of inter-racial/ethnic dating and marriage (Feliciano et al. 2011). This may be a particularly important consideration given the key role that intermarriage plays in structural assimilation and boundary blurring (Alba and Nee 2003). Finally, social boundaries are likely to be more salient to the extent that they are reinforced in physical space (Park 1925).

Though largely developed prior to the dramatic increases in Hispanic immigration, the emergent ethnicity perspective may be particularly relevant for Hispanics in contemporary U.S. society. Between 1980 and 2009 the Hispanic population in the U.S. more than tripled, increasing from 14.6 million (4.7\% of the total population) to over 48 million (14\% of the total population). During this time the Hispanic population continued to experience pronounced residential concentrations. In 2010, the average Hispanic lived in a community where 46 percent of the residents were Hispanic, and between 1980 and 2010 Hispanic segregation (measured by the dissimilarity index) remained relatively stable while Hispanic-white isolation increased markedly, largely as a result of the continuing stream of Hispanic immigrants who tend to reside in ethnic enclaves upon arrival (Iceland 2009; Logan and Stults 2011). This continued replenishment of Hispanic immigrants into communities has likely sharpened inter-group boundaries and increased the salience and durability of ethnic identity (Jiménez 2010).

However, despite a long theoretical history and the primacy of the role that ethnic residential segregation plays in negotiating racial/ethnic boundaries, there have been few direct, systematic evaluations of how segregation affects racial identification (but see Oropesa et al. 2008). While previous research has examined how the proportion of co-ethnics in respondents' communities (or schools) relates to their racial identification (Eschbach and Gomez 1998; Landale and Oropesa 2002; Vaquera and Kao 2006), the relative size of a minority group does not capture the crucial dimension of geographic clustering that is at the heart of the emergent ethnicity perspective (i.e. segregation away from other groups). Perhaps more importantly, previous research has been unable to determine the direction of the relationship 
between community context and identification choices due to the methodological difficulty of dealing with selection bias. While theoretical and qualitative accounts point to the role of segregation as a determinant of ethnic identity, it could be the case that those who maintain a strong ethnic identity may choose to reside in an area with more co-ethnics. We address this issue by testing how segregation at the metropolitan level affects how Hispanics identify their race, as well as by using an instrumental variable approach to determine the effect of segregation on racial identification. The advantage of using inter-metropolitan variation is that it is less subject to the selection bias that characterizes within metro area (i.e., neighborhood) residential choices (Cutler and Glaeser 1997). We detail the strengths of this approach more fully in the methods section.

\section{Racial Identification in Anti-Immigrant Times}

The reactive ethnicity perspective holds that Hispanics' identifications depend largely on the context of the reception they encounter in the United States. One of the primary determinants is the degree of discrimination and prejudice they experience. According to Portes and Rumbaut (1990), reactive ethnicity develops "in reaction to the situation, views and discrimination" that turn ethnicity or "national origin into the primary basis of group solidarity, overwhelming other competing identifications" (p. 96). In response to large scale immigration, Latin Americans have often been portrayed in the media as "invaders" and dangerous to America's culture, society, security and economy (Chavez 2008). Consistent with this narrative, Harvard political scientist Samuel Huntington (2004) argues "the persistent inflow of Hispanic immigrants threatens to divide the United States into two peoples, two cultures, and two languages. Unlike past immigrant groups, Mexicans and other Latinos have not assimilated into the U.S. culture, instead forming their own political and linguistic enclaves... and rejecting the Anglo-Protestant values that built the American Dream" (p. 1). This anti-immigrant framing has been exacerbated by the deteriorating U.S. economy as well as the perceived link between immigration and national security. In the mid 2000s 74 percent of Americans rated immigration as a moderately big or very large national problem (Kohut and Suro 2006) and between 2002 and 2007 hate crimes against Hispanics increased by 30 percent (FBI 2009).

Though largely discussed as a general anti-Hispanic trend in the extant literature, there is considerable geographic variability in anti-Hispanic sentiment and discrimination. For example, a 2006 poll showed that 46 percent of respondents in Phoenix believed that Latin American immigrants significantly increase crime, while only 30 percent of Chicago residents held this view (Kohut and Suro 2006). There is also substantial geographic variability in the distribution of anti-Hispanic violence. In New York there were 112 anti-Hispanic hate crimes between 2006 and 2008 , but only 24 in Chicago. The implication is that certain metropolitan areas experience greater levels of prejudice and violence aimed at Hispanics.

According to the reactive ethnicity perspective, the result of such anti-Latino contexts is the brightening and hardening of the social boundaries separating Hispanics from other groups in the face of perceived threats, persecution, and exclusion 
(Rumbaut 2008; Telles and Ortiz 2008). The extant literature discusses several mechanisms potentially linking anti-Hispanic discrimination to racial identifications, including: 1) the increased salience of racial group membership; 2) the internalization among Hispanics that they are perceived as racially distinct and culturally "other"; and 3) the mobilization of immigrant groups along ethnic lines to combat perceived prejudice (Rumbaut 2008). In support of this view, Massey and Sanchez (2010) found that Hispanics who had experienced discrimination were less likely to feel "American", and Golash-Boza and Darity (2008) found that Hispanics who felt discriminated against were more likely to report an "other" or "black" racial identification using data from two different national surveys of Latinos.

Yet, despite this research attention several questions remain unanswered. First, as with the segregation-identification association, it is difficult to determine the direction of the relationship between discrimination and identification. It could be the case that those more likely to promote their Hispanic or "other" racial identification are also more likely to experience discrimination. Second, the supporting evidence relies almost entirely on individual experiences with discrimination or small-scale, qualitative accounts. The result is that we know comparatively little about whether certain social contexts are more likely to promote reactive ethnicities. In this article, we attempt to address issues of selection bias by (a) measuring hate crimes at the metropolitan level, (b) using an instrumental variable approach, and (c) investigating mobility patterns to gain leverage on the direction of this relationship (discussed in the methods and results sections below).

Furthermore, by focusing only on individual level discrimination, these studies may miss the symbolic effects of vicarious victimization that are also likely affecting how Hispanics negotiate U.S. racial classifications. That is, one does not have to be a victim of discrimination to be affected by the discrimination experienced by co-ethnics in the vicinity. As one Mexican-American respondent interviewed on the subject of anti-Hispanic discrimination stated: "If there's a threat that's apparent on somebody else who is of the same descent that I am, and the other person is being totally racist about it and it's all just hate of color, that's when my background comes to be more important to me" (Jiménez 2010).

In this article we go beyond prior research by examining how the level of antiHispanic hate crime in a metropolitan area affects how Hispanics classify their 'race'. In doing so, we offer one of the first systematic analyses of the role that communities characterized by high levels of anti-Hispanic discrimination may play in determining how Hispanics negotiate racial/ethnic boundaries.

\section{Theoretical Statement}

Our core theoretical argument is that certain environments condition the boundary negotiations that occur among Hispanics as they encounter the U.S. racial order. More specifically, social contexts that heighten intergroup boundaries between Hispanics and non-Hispanics increase the salience of their ethnic or national origin identities, thus decreasing the likelihood that they view their 'race' as distinct from these identities and decreasing the likelihood that they identify with one of the existing U.S. racial classifications. 
Consistent with the emergent ethnicity perspective, by limiting interaction with out-group members, promoting local institutions based on ethnic group identification, and reinforcing social boundaries in physical space, we hypothesize that highly segregated areas will increase the salience of group boundaries, and thus Hispanics will be more likely to opt out of the existing racial classifications by choosing the "other race" category. Drawing from the reactive ethnicity perspective, we further predict that Hispanics living in areas that experience higher levels of anti-Hispanic hate crime will be more likely to reactively assert their Hispanic or national origin identification, and also opt out of the existing racial classification system by choosing the "other race" category. While contemporary accounts have tended to treat the emergent and reactive ethnicity perspectives as conceptually distinct, we do not view them as necessarily competing, and in fact we argue they can be usefully combined to predict a third hypothesis: the effects of segregation on racial boundary identifications will be particularly pronounced where there are also high levels of prejudice, and vice versa. This view is consistent with foundational accounts on the formation of ethnic group identity, particularly the work of Robert Park (1925) who theorized that "areas of population segregation tend to preserve and, where there is racial prejudice, to intensify the intimacies and solidarity" of local ethnic groups (our emphasis, pp. 9-10).

\section{Data, Method, And Logic Of Analysis}

The data for this analysis come from three primary sources: individual-level data come from the 2009 American Community Survey (ACS), metropolitan-level segregation measures are derived from the 2005-2009 five-year ACS estimates, and information on anti-Hispanic hate crimes come from the FBI Uniform Crime Reports for 2006-2008. To obtain valid self-report measures of race and ethnicity, we limit our analysis to Hispanic householders for whom the information on race and Hispanic origin were not imputed. Further, we limit our analysis to only those Hispanics who live in metropolitan statistical areas (MSAs) as the ACS does not provide geographic information on respondents who live in communities with less than 100,000 people. Our final sample consists of 93,432 Hispanic respondents living within 264 metropolitan areas.

\section{Dependent Variable}

Our dependent variable is the self-reported race among Hispanic respondents. Because the census treats Hispanic ethnicity and race as distinct constructs, we are able to investigate how Hispanics negotiate their racial identifications in response to the government racial classification system. Previous research indicates that states play a key role in establishing categorical boundaries around population groups and "state-sanctioned racial classification schemas form the basis of popular perception and are linked to economic resources and political power through construction of individual and collective identification" (Frank et al. 2010: 385). Thus, how Hispanics respond to government classifications offers important insights into how they may be affecting the existing racial order. 
Given our emphasis on the determinants of the 'other race' category, we use a dichotomous measure where 1 equals 'some other race' and 0 equals any current U.S. racial classification (i.e. white alone, black alone, Asian/Pacific Islander or American Indian/Alaska Native ${ }^{2}$, and two or more races). We chose this more general approach for three primary reasons. First, our hypotheses suggest Hispanics either attempt to reconcile their self-identifications within the U.S. classifications or identify outside of them. Thus, the critical distinction is between existing racial categories which treat race and ethnicity separately and other potential racial classifications. Second, the instrumental variable procedure used in this study does not yet accommodate multinomial logistic regression, thus precluding simultaneous modeling of each racial category option. Still, as we demonstrate in the Appendix, the pattern of results shown in the text is consistent when we: (1) examine each two-way combination separately (e.g. white-other race, black-other race, etc.), (2) allow for multiple racial categorizations (e.g. those identifying as both "white" and "other race" — see Supplement, Table 1), and (3) estimate multinomial logistic regression models without the instrumental variables.

Finally, we interpret the "other race" category as a meaningful identificationone that indicates the rejection of existing U.S. classifications and has implications for social relations. However, we note that the imposed categories on census forms likely produce misclassification bias. That is, the identifications respondents chose on the census would likely be different if other racial options were provided. For example, Campbell and Rogalin (2006) found that many Latino respondents who indicated 'white' when race and ethnicity were asked separately switched to a Latino racial category when offered a combined racial/ethnic origin question. Still, we view how Hispanics respond to these classifications as substantively important and theoretically telling. As Frank et al. (2010) state, "it is precisely this type of [misclassification] bias that deserves examination. Essentially, the question is not how Latinos ideally define themselves given all available options, but how they respond when faced with the limitations of the existing racial categorization system" (p. 385). The main contribution of our study is investigating how the social context in which Hispanics negotiate their available racial options affects whether they accept, challenge, or expand the official U.S. racial boundaries.

\section{Focal Independent Variables}

Our first focal independent measure is the level of Hispanic/Non-Hispanic segregation at the metropolitan level. While racial/ethnic identification is likely to affect neighborhood residential choices, the advantage of comparing outcomes across entire metropolitan areas is that individuals are less likely to be selected into metropolitan areas in ways that are systematically related to racial/ethnic boundaries. Though this approach does not account for all non-random selection bias, these estimates are far less likely to be confounded by the high selectivity related to racial/ethnic affiliations characteristic of intra-metropolitan neighborhood choices (Cutler and Glaeser 1997).

We use the index of dissimilarity $(D)$, which captures the unequal distribution of Hispanics within a given metropolitan $\operatorname{area}^{3}$. We compute $(D)$ for each metropoli- 
tan area using tract-level data based on the 2008 MSA boundaries. Metropolitan areas are typically chosen as the broader unit when calculating segregation indexes because they are reasonable approximations of housing markets. The index ranges from 0 (complete integration) to 100 (complete segregation) and indicates the percentage of Hispanics that would have to move to achieve an even spatial distribution with non-Hispanics in tracts across the metropolitan area.

Our second focal independent variable is the number of victims of anti-Hispanic hate crimes (logged) reported by the police in a metropolitan area from 2006 to $2008^{4}$. This period is temporally prior to our dependent measure and we combine three years to reduce year-to-year fluctuations. We use hate crimes as our measure of anti-Hispanic sentiment because unlike other forms of discrimination, such as employment or wage discrimination, hate crimes carry symbolic power beyond the individual victims with implications of group suppression through intimidation and violence (King et al. 2009). Given the symbolic significance of hate crimes aimed at particular groups, we utilize the count of victims rather than the rate because we think it is far more likely that Hispanics' perceptions of discrimination will be influenced by the number of incidents of anti-Hispanic prejudice, rather than "adjust" the number of incidents in the metropolitan area to "probabilities" based on the size of the population at risk (cf.King et al. 2009; Tolnay et al. 1996). We think this is especially the case given the divisive effects on communities and the significant media and informal attention surrounding hate crimes, and we offer an illustrative example to underscore how hate crimes affect Hispanic communities.

In 2010 two white teenagers were convicted in Scranton, Pennsylvania of a federal hate crime for the killing of Luis Eduardo Zavala, an undocumented Mexican immigrant. Since the attack in July 2008 there have been over 650 news articles published on the incident in Pennsylvania news sources ${ }^{5}$. As with many hate crimes, reports indicate the incident polarized the community, exposing and intensifying ethnic tensions which mobilized feelings of out-group hostility and in-group solidarity among Hispanics, many of whom organized with immigrants' rights groups to pressure the Justice Department to prosecute the teenagers for a federal hate crime. As a lawyer for the Mexican American Legal Defense and Educational Fund stated, "for many Latinos, this is a case of enough is enough... and it can help us get attention to the wider issue that this is happening all over the country, not just to illegal immigrants, but legal, and anyone who is perceived to be Latino (Hamill 2008: A12)." While the case involved only one victim, the attack mobilized the larger Hispanic community who felt vicariously victimized by the symbolic messages of anti-Hispanic hate and violence. Consistent with this example, we think perceptions of anti-Hispanic prejudice are likely to be more affected by the frequency of such events, rather than the adjusted rate of victimizations.

\section{Contextual Variables}

We attempt to isolate the effects of segregation and anti-Hispanic prejudice by including a host of contextual measures at the metropolitan level. Fundamentally important is percent Hispanic in the metropolitan area; by accounting for the relative size of the Hispanic population, our models can determine whether the geographic 
concentration of Hispanics away from non-Hispanic groups actually matters, or alternatively, if racial identification is simply affected by how numerous Hispanics are relative to the general population regardless of their geographic clustering. This measure also ensures that our hate crime variable is not confounded by the relatively large Hispanic presence in certain metropolitan areas. Drawing from Cornell and Hartmann's (2007) discussion of identity "construction sites," we also account for two critical contextual factors that are common locations of ethnic and racial identity formation-immigrant labor market clustering measured as the percent of workers in manual labor occupations ${ }^{6}$ and economic opportunity, as measured by the percent of Hispanics in poverty and the unemployment rate. Given that Latinos account for half of the U.S. population growth since 2000 (Fry 2008), we also include a measure of the percent new construction within a metropolitan area. Finally, extant research on identity and immigration settlement patterns suggests region plays an important role in residential choices and racial identification (Iceland 2009; Rumbaut 2009).

\section{Individual Variables}

Drawing on previous research (Oboler 1995; Tafoya 2005; Vacquera and Kao 2006), we account for a number of individual level characteristics that have been shown to affect Hispanics' racial self-identifications, including: national origin (with a series of dichotomous variables for Puerto Rican, Cuban, and 'other' country of origin, with Mexicans serving as the reference category), education (dichotomous measures for less than high school [reference], high school graduate, some college, and college graduate), household income (dummy variables for those 100-199 percent above the poverty line, 200-299 percent above, and those whose household incomes are 300 percent or greater above the poverty line, with those below the poverty line are the reference category), English language ability (is English the primary language spoken at home? $[1=$ yes $])$, gender $(1=$ male), marital status $(1=$ married $)$, and a continuous measure of age.

Finally, we include a dichotomous measure for foreign-born status ( $1=$ foreign born) and devote considerable empirical attention to nativity because prior research demonstrates that foreign-born and native-born Hispanics encounter the U.S. racial classification system with different normative frameworks of racial boundaries. While native-born Hispanics have encountered the white/black dichotomy that characterizes much of the U.S. race relations, the racial classifications in much of Latin America are more finely gradated along a white-black continuum (Denton and Massey 1989). It is possible that these differing views of racial boundaries may condition how individuals respond to their social context, an empirical question we evaluate in this study.

\section{Instrumental Variables}

While our use of inter-metropolitan variation and the inclusion of multiple contextual and individual controls help reduce the amount of bias in our estimates of segregation and hate crime, it does not eliminate it. A broader concern is that our results may reflect omitted metropolitan characteristics that are causing certain metropolitan areas to have higher levels of segregation and hate crimes, and affect 
Hispanics' racial identifications. We attempt to alleviate these concerns by using an instrumental variable (IV) approach for both of our focal predictors. An IV approach involves first regressing the key predictor variable (i.e. the treatment) on an exogenous measure (i.e. the instrument) that is unrelated to the outcome measure (except indirectly through the treatment). The outcome measure is then regressed on the predicted treatment variable from the first equation. The goal of this approach is to remove the spurious correlation between the explanatory variable and unobserved characteristics. By using only that portion of the variability in the treatment variable (in our case, segregation and hate crime are conceived as "treatments") that is uncorrelated with the omitted variables to estimate the causal relation between the treatment and outcome, an IV helps remedy the issue of omitted variable bias (Angrist and Krueger 2001).

Drawing from the 2002 Census of Governments, we use the number of municipal and township governments (logged) to instrument our measure of segregation ${ }^{7}$. This instrument is theoretically appropriate for our study because the number of local governments are unlikely to directly affect racial identifications, but are likely to shape segregation through a Tiebout mechanism: more local governments result in greater variation in tax rates and services within a particular MSA, thus encouraging the desire for sorting. Sensitivity tests presented in the Supplement support the strength of both of our instrumental variables. Formally, we specify equation 1 as follows:

$$
S_{i}=\beta_{0 i}+\beta_{1} Z_{i}+W_{i} \lambda+\xi_{i}
$$

where segregation $\left(S_{i}\right)$ is a function of the instrumental variable $Z_{i}$ (logged number of municipal and township governments), a vector of ecological and individual level controls and random error. While we use the number of governments as an exogenous source of variation, in the absence of randomized assignment it is not necessarily the case that the treatment and control groups are identical. We thus account for key ecological and individual controls in the first stage equation to account for any observed differences across groups, which increases our statistical efficiency by reducing sampling variance.

The second stage of the two-stage estimation process models the dependent variable (racial self-identification) as a function of the predicted $S_{i}$ from Equation 1 and a vector of control variables $D_{i}{ }^{8}$ :

$$
X_{i}^{*}=\alpha \hat{S}_{i}+\beta_{k} D_{i k}+u_{i}
$$

where $X_{i}=0$ if $X_{i}^{*}<0, X_{i}=1$ if $X_{i}^{*} \geq 0$, and $u_{i} \sim N(0,1)$. The coefficient $\alpha$ is the key parameter of interest, determining whether living in segregated metropolitan areas influences Hispanics' racial self-identifications.

To our knowledge no prior research has investigated anti-Hispanic hate crimes using instrumental variables, and thus we were unable to rely on previous studies to guide our instrument choice. Guided by theoretical considerations, we instrument our hate crime measure with the level of total violent crime within each metropolitan area. While previous research demonstrates that hate violence results from intergroup tension and conflict (Tolnay et al. 1996), it is likely that hate crimes are more likely to occur in places that already experience higher levels of violence. In 
other words, many metropolitan areas have witnessed significant increases in their resident Hispanic population, which likely heightens inter-group tensions, but it is probable that these tensions are more likely to manifest into hate crimes in areas where violence is already prevalent. If this is the case, then the level of violent crime in each metropolitan area may be an appropriate instrument as it is likely to affect the level of anti-Hispanic hate crimes but is unlikely to directly shape Hispanics' racial identifications. However, because violent crime itself is a manifestation of various complex social phenomena, and because there is no precedent for this approach in the literature, we interpret our IV results with appropriate caution and report them alongside non-IV probit regressions to demonstrate that our findings are not dependent on this single methodological choice.

Using Uniform Crime Report data provided by the FBI, we instrument our hate crime measure with the level of violent crimes reported to the police for the years 2003-2005 ${ }^{9}$. These data have several strengths for our purposes. First, the years are temporally prior to our focal measure. Second, violent crimes are more reliably reported to the police. Finally, three years reduces the influence of year-to-year fluctuations. The specification of the two-step IV models for our hate crime measure is identical to equations 1 and 2 above; the only difference is that we substitute the number of hate crimes in place of segregation and the logged number of violent crimes in place of the logged number of municipal and township governments. In all models we adjust the standard errors to account for the interdependence of individuals within metropolitan areas ${ }^{10}$.

\section{Results}

Table 1 reports the descriptive statistics for all measures by self-reported race. Of the roughly 93,000 Hispanics in our sample, 72 percent identified within one of the existing U.S. racial categories and 28 percent identified as 'some other race.' Of those who identified within the U.S. classification system, 90 percent self-identified as 'white' (results not shown). This pattern of racial identification suggests that how Hispanics will ultimately shape the color line will likely be determined by whether they will one day expand the meaning of "whiteness" as Southern and Eastern Europeans did a century ago, or maintain a distinct racial identification. Next we investigate whether these racial identifications vary for Hispanics who reside in metro areas with different levels of segregation and anti-Hispanic hate crimes.

Consistent with theoretical expectations, Figure 1 reveals those who reside in areas characterized by high levels of segregation from non-Hispanics and high levels of crime motivated by anti-Hispanic bias are substantially more likely to mark "other race" compared to Latinos in other metropolitan contexts. Indeed, Hispanics in the 'high-high' category are nearly twice as likely to identify as 'other race' than Latinos in areas with low levels of hate crime and segregation (e.g. the 'low-low' category).

However, these results are only tentative as they could be driven by other contextual and individual-level factors. Further, t-tests revealed significant differences on multiple measures (results not shown) for Hispanics in these different contexts 
Table 1: Descriptive Statistics of Hispanic Racial Identification, American Community Survey 2009

\begin{tabular}{|c|c|c|c|c|}
\hline & & Total & Existing Racial Category & Other Race \\
\hline & Number & 93,432 & 67,629 & 25,803 \\
\hline & Percent of all Hispanics & 100 & 72.3 & 27.6 \\
\hline \multicolumn{5}{|l|}{ Independent Measures } \\
\hline \multirow[t]{2}{*}{ Focal Measures } & Hispanic / Non-Hispanic D & 44.9 & 44.5 & 46 \\
\hline & (ln) Anti-Hispanic Hate Crimes & 3 & 2.8 & 3.5 \\
\hline \multirow[t]{9}{*}{ Contextual Variables } & Percent Hispanic & 30.7 & 31.3 & 29.2 \\
\hline & Percent Hispanic Poverty & 21.5 & 21.5 & 21.3 \\
\hline & Percent Unemployed & 7.4 & 7.4 & 7.4 \\
\hline & Percent Manual Labor & 30.7 & 30.9 & 30.3 \\
\hline & Percent New Construction & 12.6 & 13.2 & 11.3 \\
\hline & Northeast (reference) & $15.8 \%$ & $13.9 \%$ & $20.3 \%$ \\
\hline & Midwest & $8.3 \%$ & $7.6 \%$ & $9.8 \%$ \\
\hline & South & $36.2 \%$ & $40.7 \%$ & $25.8 \%$ \\
\hline & West & $39.6 \%$ & $37.7 \%$ & $44.1 \%$ \\
\hline \multicolumn{5}{|l|}{ Individual Variables } \\
\hline \multirow[t]{6}{*}{ Nativity } & Mexican (reference) & $59.1 \%$ & $58.4 \%$ & $60.6 \%$ \\
\hline & Puerto Rican & $11.0 \%$ & $10.9 \%$ & $11.3 \%$ \\
\hline & Cuban & $5.1 \%$ & $6.9 \%$ & $1.0 \%$ \\
\hline & Other Hispanic & $24.8 \%$ & $23.8 \%$ & $27.1 \%$ \\
\hline & Native Born (reference) & $39.0 \%$ & $42.1 \%$ & $31.6 \%$ \\
\hline & Foreign Born & $61.0 \%$ & $57.9 \%$ & $68.4 \%$ \\
\hline \multirow[t]{8}{*}{ Socioeconomic } & Less than H.S. (reference) & $35.3 \%$ & $32.5 \%$ & $42.1 \%$ \\
\hline & H.S. Graduate & $24.5 \%$ & $24.1 \%$ & $25.5 \%$ \\
\hline & Some College & $25.4 \%$ & $26.4 \%$ & $23.2 \%$ \\
\hline & College Graduate & $14.7 \%$ & $17.0 \%$ & $9.2 \%$ \\
\hline & Below Poverty (reference) & $21.6 \%$ & $20.9 \%$ & $23.5 \%$ \\
\hline & $100-199 \%$ Poverty Status & $27.2 \%$ & $26.2 \%$ & $29.5 \%$ \\
\hline & $200-299 \%$ Poverty Status & $18.4 \%$ & $18.0 \%$ & $19.3 \%$ \\
\hline & $>300 \%$ Poverty Status & $32.8 \%$ & $34.9 \%$ & $27.8 \%$ \\
\hline \multirow{7}{*}{$\begin{array}{l}\text { Acculturation } \\
\text { Other Controls }\end{array}$} & Speaks English at Home & $79.9 \%$ & $76.7 \%$ & $87.2 \%$ \\
\hline & Married & $53.0 \%$ & $53.4 \%$ & $52.1 \%$ \\
\hline & Age & 44.1 & 45 & 42.2 \\
\hline & Female (reference) & $45.2 \%$ & $45.6 \%$ & $44.4 \%$ \\
\hline & Male & $54.8 \%$ & $54.4 \%$ & $55.6 \%$ \\
\hline & Non-Central City (reference) & $72.0 \%$ & $74.6 \%$ & $66.0 \%$ \\
\hline & Central City & $28.0 \%$ & $25.4 \%$ & $34.0 \%$ \\
\hline
\end{tabular}

Sources: The Hispanic/Non-Hispanic Dissimilarity index, \% Hispanic, \% Poverty, \% Unemployed, \% Manual Labor, and $\%$ New Construction are calculated from 2005-2009 American Community Survey based on 2008 Census metropolitan boundary definitions. The hate crime data come from FBI Uniform Crime Reports aggregated to the MSA level for the years 2006 through 2008. All other measures come from the 2009 American Community Survey.

Note: Total N's for each category are unweighted. Frequencies represent the weighted distributions. 


\section{Other Race}

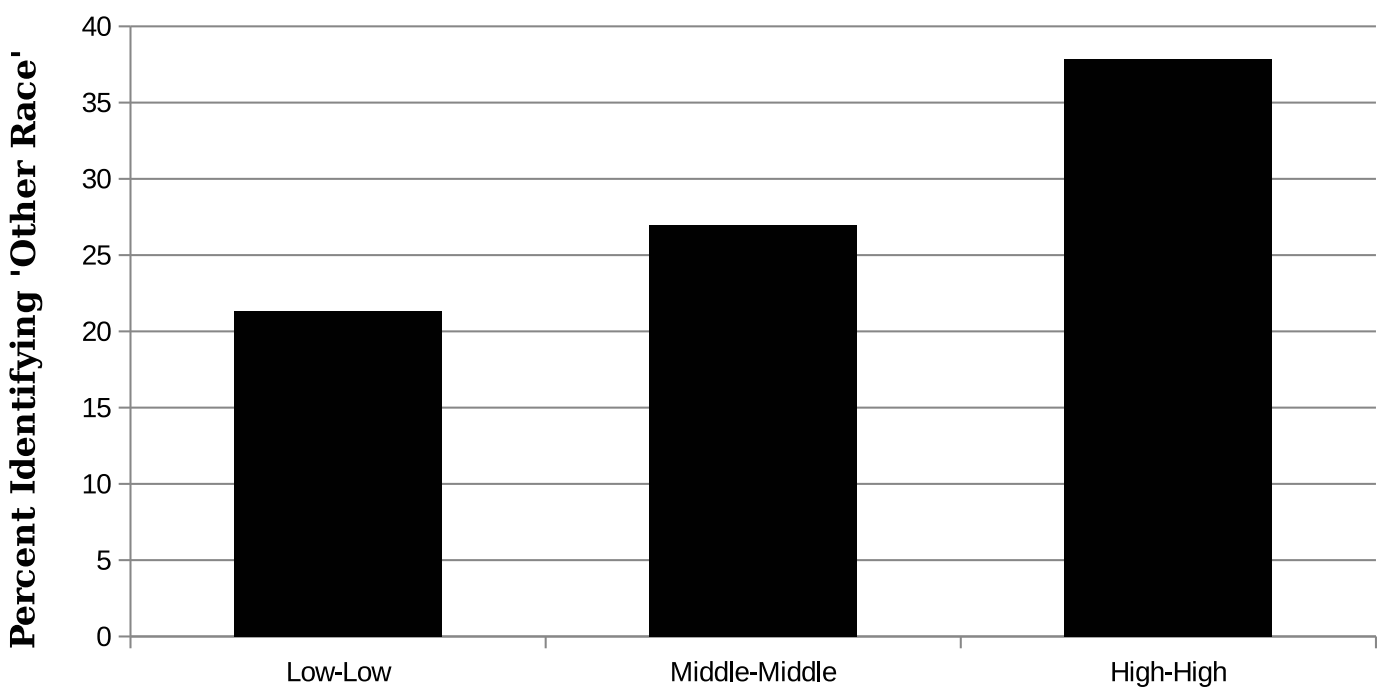

Figure 1: Hispanic Racial Identification by Segregation and Levels of Hate Crime

Note: "Low-Low" represents the lowest terciles of Hispanic D and ( $\ln$ ) Anti-Hispanic Hate Crimes. Examples of"Low-Low" MSAs include Albuquerque, NM and Orlando, FL."Middle-Middle" represents the middle terciles of Hispanic D and (ln) Anti-Hispanic Hate Crimes. Examples of "Middle-Middle" MSAs include Dallas-Fort Worth, TX and Denver, CO."High-High" represents the highest terciles of Hispanic D and (ln) anti-Hispanic Hate Crimes. Examples of "High-High" MSAs include Los Angeles, CA and Boston, MA.

that could potentially confound any association between segregation, anti-Hispanic hate, and racial self-identification.

\section{Multivariate Results}

Models 1 and 2 of Table 2 provide the baseline estimates for our focal measures net of all individual level controls. For parsimony we report only the coefficients of interest (full models are in the appendix). The results in model 1 support the emergent ethnicity perspective; Latinos residing in metropolitan areas with higher levels of Hispanic/Non-Hispanic segregation are more likely to opt out of the U.S. racial classifications by choosing the 'other race' category. Turning to the findings for anti-Hispanic hate crimes, the results from model 2 are in line with the reactive ethnicity perspective; net of individual controls, the likelihood of choosing 'other race' increases with the level of anti-Hispanic hate crime in a metro area. These results suggest that in prejudiced community contexts Hispanics are more likely to reactively assert their 'other' racial identification, and offers some support that symbolic violence aimed at groups has implications for how individuals negotiate their shared identities.

In model 3 we find some support for our third hypothesis by interacting Hispanic/Non-Hispanic segregation by the level of anti-Hispanic hate crimes. The interaction effect is in the expected positive direction, and the marginally significant 
Table 2: Probit Estimates of Hispanic 'Other Race' Identification: Instrumenting with Number of Governments and Violent Crimes, American Community Survey 2009

\begin{tabular}{lcccccc}
\hline Focal Measures & $(1)$ & $(2)$ & $(3)$ & $(4)$ & $(5)$ & $(6)$ \\
\hline Hispanic / Non-Hispanic Dissimilarity & $0.011^{*}$ & & NS & $0.031^{\dagger}$ & & NS \\
& $(0.006)$ & & & $(0.007)$ & & \\
(ln) Anti-Hispanic Hate Crimes & & $0.093^{\dagger}$ & NS & & $0.056^{\dagger}$ & NS \\
& & $(0.017)$ & & & $(0.02)$ & \\
Dissimilarity x (ln) Hate Crimes & & & $0.004^{*}$ & & & $0.003^{*}$ \\
& & & $(0.002)$ & & & $(0.002)$ \\
Model Specification & Yes & Yes & Yes & Yes & Yes & Yes \\
Individual Controls? & No & No & No & Yes & Yes & Yes \\
Contextual Controls? & No & No & No & Yes & No & No \\
IV (ln) Governments (2002)? & No & No & No & No & Yes & No \\
IV (ln) Violent Crime (2003-2005)? & 93,432 & 93,432 & 93,432 & 93,432 & 93,432 & 93,432 \\
N & &
\end{tabular}

Notes: Significance tests are calculated from robust standard errors (reported in parentheses). NS represents effects are not statistically significant at $\mathrm{p} \leq 10 . * \mathrm{p}<.10 ;+\mathrm{p}<.05$.

coefficient indicates Hispanics are more likely to identify as 'other race' in areas that have both higher levels of segregation and higher levels of prejudice.

In models 4 and 5 we introduce our instrumental variables and contextual controls, and the results suggest that the effects for segregation and hate crimes are consistent. The findings in model 4 suggest that the social context of Hispanic segregation is a significant predictor of Hispanics' racial self-identification and that this relationship remains with the inclusion of our instrument and a host of additional contextual variables. According to the probit results, a one unit increase in dissimilarity increases the probability of self-identifying as 'other race' by .03 . Interpreted substantively, the predicted probability of choosing 'other race' increases from .258 to .334 with a one standard deviation increase in Hispanic segregation while holding all other individual and contextual variables constant. The IV results in model 5 indicate the relationship between anti-Hispanic hate violence and racial self-identity also holds. A one standard deviation increase in anti-Hispanic hate crimes increases the predicted probability of opting out of U.S. racial classifications from .255 to .287 .

The final model in Table 2 tests the interaction effect between segregation and hate crimes net of individual and contextual controls ${ }^{11}$. Consistent with the pattern observed in model 3, we find evidence that the effects of segregated contexts on Hispanics' racial boundaries are pronounced when there are also higher levels of hate-motivated crime towards Hispanics. These findings may have implications for predictions regarding the U.S. color line. Recall that in Figure 1 the population of Hispanics in the "high-high" category was over 45 percent larger than the population in the "low-low" contexts. In other words, Hispanics are significantly more 
Table 3: IV Probit Estimates of Hispanic 'Other Race' Identification by Nativity Status, American Community Survey 2009

\begin{tabular}{|c|c|c|c|c|}
\hline \multirow{4}{*}{$\begin{array}{l}\text { Focal Measures } \\
\text { Hispanic/Non-Hispanic Dissimilarity }\end{array}$} & \multicolumn{2}{|c|}{ Segregation Effects } & \multicolumn{2}{|c|}{ Hate Crime Effects } \\
\hline & (1) & (2) & (3) & (4) \\
\hline & Native Born & Foreign Born & Native Born & Foreign Born \\
\hline & $0.025^{\dagger}$ & $0.037^{+}$ & & \\
\hline & $(0.005)$ & $(0.010)$ & & \\
\hline \multirow[t]{2}{*}{ (ln) Anti-Hispanic Hate Crimes } & & & $0.052^{\dagger}$ & $0.057^{\dagger}$ \\
\hline & & & $(0.017)$ & $(0.024)$ \\
\hline \multicolumn{5}{|l|}{ Model Specification } \\
\hline$\overline{\text { Individual Controls? }}$ & Yes & Yes & Yes & Yes \\
\hline Contextual Controls? & Yes & Yes & Yes & Yes \\
\hline IV (ln) Governments (2002)? & Yes & Yes & No & No \\
\hline IV (ln) Violent Crime (2003-2005)? & No & No & Yes & Yes \\
\hline $\mathrm{N}$ & 38,132 & 55,300 & 38,132 & 55,300 \\
\hline
\end{tabular}

Notes: Models 1 and 3 are estimated on only native born Hispanics. Model 2 and 4 are estimated on foreignborn Hispanics. Significance tests are calculated from robust standard errors (reported in parentheses). $* \mathrm{p}<$ $.10 ;+\mathrm{p}<.05$

likely to experience high levels of metropolitan segregation and anti-Hispanic hate crimes than low levels.

Taken together, these results offer suggestive evidence that certain social contexts influence how Hispanics racially identify, and that areas with higher levels of segregation and prejudice may heighten the social boundaries between Hispanics and other groups. As a consequence, Hispanics are more likely to eschew state recognized racial categories and instead identify as 'some other race.' In the next section we investigate whether this pattern of results is moderated by nativity status.

\section{Nativity Differences?}

Table 3 reports the results of IV probit models predicting 'other race' identification for native and foreign-born Hispanics separately for our focal measures. Models 1 and 2 report the effects of Hispanic segregation and models 3 and 4 display the Hispanic hate crimes results. The findings presented in these models are consistent with the inferences derived in Table 2. Comparing the direction, magnitude, and significance across these models, we find that the relationships between segregation, prejudice, and racial identification are consistent among both native and foreign born Hispanics.

\section{Endogeneity Concerns}

While our instrumental variable approach helps allay concerns that the relationships between segregation, hate crime, and racial identification are driven entirely 
by omitted variables, a more difficult issue to deal with is selective migration. Hispanics who are more likely to self-identify as white or other existing classifications may be more likely to move out of highly segregated and prejudiced areas. To address this issue we utilize information on mobility patterns in the ACS, which asks respondents about their place of residence 1 year prior. Specifically, we relate current racial identification choices to segregation and hate crime in the metropolitan area of residence in the year preceding the survey, instrumenting with the local government and violence variables in the city of residence in 2008. These additional analyses include only those living in a metropolitan area in $2008(\mathrm{~N}=91,594)$.

Models 1 and 2 of Table 4 report the results from this analysis, and the findings align with the IV findings shown in Table 2. Specifically, higher levels of metropolitan segregation and anti-Hispanic hate crime significantly increase the likelihood of choosing 'some other race.' A final test of the possible bias from migration patterns are shown in models 3-6, where we run identical models for those individuals who did and did not move between 2008 and 2009 (13 percent moved). If the observed relationships are due to selective migration, we should see distinct effects for "movers" and "stayers." This does not appear to be the case. The results in models 3-6 are substantively similar to the results in models 1 and 2. This suggests that migration based on racial identification choice does not explain the pattern of results for the focal measures in our analysis.

In summary, findings suggest Hispanics are more likely to identify outside U.S. racial classifications when they reside in more segregated and prejudiced contexts. These findings hold across nativity status and migration patterns, and as we demonstrate in the appendix, they also hold under alternative specifications of the dependent variable and estimation procedures. That said, we fully acknowledge that determining casual effects is notoriously difficult in non-experimental social research and call for further tests of these ideas before strong conclusions are reached.

\section{Discussion and Conclusion}

The growth of the Hispanic population has increased uncertainty about the future of the U.S. color line. While the majority of Hispanics mark "white," over 18 million Hispanics identified as "other race" on the 2010 census. Whether Hispanics will one day expand the boundaries of whiteness or eventually create a new "race" category is dependent on the salience of racial/ethnic boundaries for both in-group and out-group members. An important question for the future of racial identification in the U.S. is what determines the salience of these boundaries. In this article we argued that an important, yet under-researched dimension is the residential context in which boundary negotiations occur.

Consistent with the emergent ethnicity perspective, our results suggests that Hispanics are more likely to opt out of the U.S. racial classifications by choosing the 'other race' category in metropolitan areas characterized by higher segregation from non-Hispanics. This might suggest that in such contexts, Hispanics are more likely to see themselves as a distinct racial category, apart from the traditional options that define the U.S. racial landscape. This finding may have important 
Table 4: Sensitivity Analyses: IV Probit Estimates of Hispanic 'Other Race' Identification by Mobility Patterns, American Community Survey 2009

\begin{tabular}{lcccccc}
\hline & \multicolumn{2}{c}{ Hispanics in Metro } & \multicolumn{2}{c}{ Only Movers } & \multicolumn{3}{c}{ Only Stayers } \\
& Areas in $2008-09$ & & & \\
Focal Measures & $(1)$ & $(2)$ & $(3)$ & $(4)$ & $(5)$ & $(6)$ \\
\hline Hispanic / Non-Hispanic Dissimilarity & $0.030^{\dagger}$ & & $0.031^{\dagger}$ & & $0.030^{\dagger}$ & \\
& $(0.007)$ & & $(0.008)$ & & $(0.007)$ & \\
& & $0.055^{+}$ & & $0.048^{*}$ & & $0.056^{\dagger}$ \\
(ln) Anti-Hispanic Hate Crimes & & $(0.019)$ & & $(0.025)$ & & $(0.019)$ \\
& & & & & & \\
Model Specification & Yes & Yes & Yes & Yes & Yes & Yes \\
Individual Controls? & Yes & Yes & Yes & Yes & Yes & Yes \\
Contextual Controls? & Yes & No & Yes & No & Yes & No \\
IV (ln) Governments (2002)? & No & Yes & No & Yes & No & Yes \\
IV (ln) Violent Crime (2003-2005)? & 91,594 & 91,594 & 11,840 & 11,840 & 79,754 & 79,754 \\
N & & &
\end{tabular}

Notes: All models include only individuals living in metropolitan areas in both 2008 and 2009. Models 1 and 2 estimate the effects of Hispanic segregation and anti-Hispanic hate crimes from respondents' city of residence 1 year prior. Models 3 and 4 are estimated for only those individuals who moved between 2008 and 2009. Models 5 and 6 are estimated on respondents who did not move over the study period. Significance tests are calculated from robust standard errors (reported in parentheses). $* \mathrm{p}<.10 ;+\mathrm{p}<.05$.

implications for the future of racial/ethnic boundaries. While lower than the level of segregation experienced by blacks, Hispanics are still fairly segregated from other groups in the U.S. Perhaps more importantly, unlike black segregation, which has declined significantly since 1980, Hispanic/Non-Hispanic segregation has shown only minor declines (Logan and Stults 2011). Our results suggest that segregation from non-Hispanics potentially heightens the salience of inter-group boundaries, and the extent to which segregation increases or decreases in the coming years will affect the degree to which Hispanics opt out of the U.S. racial classifications.

We also find that Hispanics were more likely to identify as 'other race' in areas with higher levels of anti-Hispanic hate crime. The reactive ethnicity perspective offers a plausible theoretical explanation for this finding. It could be that the symbolic nature of hate crime affects Hispanics' boundary negotiations by brightening the boundaries between Hispanics and other groups. We find that these effects may be more pronounced in areas that also have higher levels of segregation. This finding, too, has important implications for the future of the U.S. color line. In recent years Hispanics have encountered a hostile context of reception-one where Latinos have often been framed as a threat to the cultural integrity of the nation in both media and academic outlets, debates about immigration have been vitriolic, and public opinion has consistently viewed ongoing immigration negatively, particularly during times of economic uncertainty and recovery (Massey and Sanchez 2010). These shifts coincided with rises in anti-Hispanic hate violence, which increased by nearly 25 percent between 2004 and 2008 (UCR 2008). Because hate-motivated crime tends 
to be geographically clustered in areas with large numbers of Hispanics, these trends ensure that a substantial population of Latinos will navigate the U.S. racial landscape in contexts marred with anti-Hispanic prejudice. Our results suggest that if this trend does not abate, the number of Hispanics who identify as 'other race' on the census may increase.

We readily acknowledge several important limitations in this research. First, our use of MSA measures and IV analysis helps address issues of endogeneity, but they do not eliminate them. It is possible that Latinos with different racial backgrounds do sort into MSAs in ways that our analysis does not capture. It is precisely for this reason that more research is needed to further examine how social contexts influence racial identifications. In line with this view, future research would do well to examine segregation and prejudice at the different units of analysis. For example, while MSA level measures may be less subject to endogeneity concerns, they may also miss important proximal social processes operating at the neighbor level.

Second, our study does not include measures of skin color, which previous research demonstrates affects how Latinos identify their race (Frank et al. 2010). While the inclusion of this measure would no doubt provide a fuller picture of the determinants of Hispanic racial identification, our core argument is that certain social environments condition Hispanics' boundary negotiations, and it is unlikely that including a measure of skin tone would change our substantive results for the effects of segregation and prejudice ${ }^{12}$. It could, however, qualify the findings here by illustrating whether certain contexts have greater or lesser effects depending on the respondents' skin tone (see Oropesa et al. 2008), an empirical question for future research. In line with this view, we think future research should explore how different national origin groups within the 'Hispanic' category respond to their ecological context when classifying their 'race.' Because our study is primarily concerned with how the community context in which Hispanics reside affects the U.S. color line generally, we focused on all those who identified as Hispanic. However, due to the diverse history of migration among groups, different contexts of reception, differing cultural adaptations, and distinct opportunities for upward mobility, it may be the case that different groups are uniquely affected by their social context when negotiating racial/ethnic boundaries.

Finally, while our analysis shows the direction of the relationship between segregation, anti-Hispanic hate, and racial boundary negotiations, we are ultimately unable to identify the specific mechanisms through which these aggregate measures may affect individuals' identifications, nor the precise choices of those who report "other race." Our analysis does however provide a useful starting point for future research looking to identify and explicate these mechanisms. For example, future research would do well to further explore the themes of segregation and antiHispanic prejudice using qualitative methods with participants in communities with varying levels of each.

With these limitations in mind, our main theoretical and empirical argument remains - the social context of segregation and anti-Latino hate appears to influence whether Hispanics accept or reject official U.S. racial classifications. That hate crimes and persisting segregation have important effects on racial identification is in line with the reactive ethnicity perspective, but it also offers an important extension of 
this argument by highlighting the importance of vicarious victimization. Precisely because hate crimes are meant to affect the groups to which individuals belong, and not just the individuals themselves, Hispanics who have not experienced the direct effects of hate crimes receive the symbolic messages sent when other co-ethnics do. Thus, our analysis highlights the potential role that prejudiced community contexts may play in affecting Hispanics' racial boundary negotiations, which extends well beyond the individual experiences with discrimination stressed in prior literature. We further extend the reactive ethnicity perspective by drawing focus to community variation in anti-Hispanic prejudice. Though considerable work has emphasized how the context of reception shapes patterns of immigrant incorporation, reactive ethnicity research has tended to focus on broad societal patterns of anti-immigrant framing. Our results clearly illustrate that the context of reception matters, but goes beyond national-level trends by highlighting how the context of reception varies significantly from city to city and demonstrating that these varying contexts affect Hispanics' incorporation into the U.S. racial order.

The research on how Hispanics will change the U.S. color line has largely focused on the malleability of racial labels and has sought to understand how individuals negotiate their racial/ethnic identifications. Our study partly corroborates prior work but also goes beyond extant research by drawing attention to the ways in which larger social contexts of segregation and prejudice affect how Hispanics racially identify. While individuals ultimately make choices about how they negotiate racial/ethnic boundaries, these discussions do not take place in a vacuum, and certain social contexts provide the setting in which such negotiations take place. According to our results, these contexts can either heighten or diminish the salience of inter-group boundaries. The implication is that the future of the U.S. racial order is partly a function of how individuals negotiate racial boundaries, but is also a function of the characteristics of where their negotiations occur.

\section{Notes}

1 We use the terms "Hispanic" and "Latino" interchangeably throughout to maintain consistency with the census designations.

2 We combine the Asian, Pacific Islander, and American Indian and Alaska Native categories because they only comprise 0.3 percent, 0.1 percent, and 1.2 percent of the Hispanic population, respectively.

3 Supplemental models using Theil's $\mathrm{H}$ index showed substantively identical results to those reported.

4 Hate crime information is available at the agency level. Aggregating up to the metropolitan area required identifying the county in which agencies were located, then summing across the different counties that make up a particular metropolitan area. Because of this, our measure includes only hate crimes reported by sheriff's departments and local policing agencies, and excludes hate crimes reported by state patrols or regional police. This restriction eliminated less than 3 percent of all hate crimes. A larger concern is that not all agencies report hate crime information, and prior research has argued that non-compliance with hate crime data collection efforts may be a form of racial bias (i.e. apathy towards protecting minorities). To ensure our results were not a function of 
non-compliance, we ran supplemental models that excluded metropolitan areas where less than 90 percent of the agencies within its borders reported hate crime information over the study period. These findings were consistent with the results in our main sample. A constant of 1 was added to this measure for all MSAs prior to logging to avoid eliminating cases where there were no anti-Hispanic hate crimes from the analysis.

5 This information comes from the News Bank database (http://infoweb. newsbank. com) accessed on April 5, 2012.

6 Manual labor occupations include: food preparation and serving related occupations; building and grounds cleaning and maintenance occupations; farming, fishing, and forestry occupations; construction, extraction, and maintenance occupations; production occupations; and transportation and material moving occupations.

7 We exclude school, water, and fire districts because they are likely to change over time.

8 We estimate Equations 1 and 2 in Stata using the ivprobit command. Using the cluster function with the ivprobit command, the model standard errors account for the interdependence of individuals within metro areas.

9 Our violence measure includes all murders, rapes, robberies, and aggravated assaults reported within each metropolitan area.

10 Errors are adjusted using the "cluster" option in Stata.

11 The IV approach is not ideal for the interaction model because we were unable to find a suitable third instrument for both segregation and anti-Hispanic hate crimes. Given the consistency of results across the probit and IV probit models in Table 2, the inferences drawn from model 6 are unlikely to be overly biased.

12 For the omission of this variable to bias our results, skin tone would have to be systematically related to the metropolitan areas in which people choose to live, net of all of the other factors controlled for in our regressions. Conceptually this seems unlikely.

\section{References}

Alba, Richard. 2009. Blurring the Color Line: The New Chance for a More Integrated America. Cambridge: Harvard University Press.

Alba, Richard D., and Victor Nee. 2003. Remaking the American Mainstream: Assimilation and Contemporary Immigration. Cambridge: Harvard University Press. http://dx.doi.org/ $10.4159 / 9780674020115$

Angrist, Joshua D. and Alan B. Krueger. 2001. "Instrumental Variables and the Search for Identification: From Supply and Demand to Natural Experiments." Journal of Economic Perspectives 15:69-85. http://dx.doi.org/10.1257/jep.15.4.69.

Barth, Fredrik. 1969. Ethnic Groups and Boundaries: The Social Organization of Culture Difference. London, UK: George Allen \& Unwin.

Brown, J. Scott, Steven Hitlin, and Glen H. Elder Jr. 2006. “The Greater Complexity of Lived Race: An Extension of Harris and Sim." Social Science Quarterly 87:411-431. http: //dx.doi.org/10.1111/j.1540-6237.2006.00388.x.

Campbell, Mary E. and Christabel L. Rogalin. 2006. “Categorical Imperatives: The Interaction of Latino and Racial Identification." Social Science Quarterly 87:1030-1052. http://dx . doi.org/10.1111/j.1540-6237.2006.00414.x.

Chavez, Leo R. 2008. The Latino Threat: Constructing Immigrants, Citizens, and the Nation. Stanford: Stanford University Press. 
Cornell, Stephen and Douglas Hartmann. 2007. Ethnicity and Race: Making Identities in a Changing World. 2nd ed. Thousand Oaks, CA: Pine Forge Press.

Cutler, David M., and Edward L. Glaeser. 1997. “Are Ghettos Good or Bad?” The Quarterly Journal of Economics 112:827-872. http://dx . doi .org/10.1162/003355397555361.

Denton, Nancey A. and Douglas S. Massey. 1989. “Racial Identity among Caribbean Hispanics: The Effect of Double Minority Status on Residential Segregation." American Sociological Review 54:790-808. http://dx. doi .org/10.2307/2117754.

Eschbach, Karl and Christina Gomez. 1998. "Choosing Hispanic Identity: Ethnic Identity Switching Among Respondents to High School and Beyond." Social Science Quarterly 79:74-90.

Federal Bureau of Investigation. 2009. Hate Crime Statistics. Washington, DC. Retrieved July 20, 2011 (http://www.fbi.gov/ucr/ucr.htm\#hate).

Feliciano, C., R. Lee, et al. 2011. "Racial Boundaries among Latinos: Evidence from Internet Daters' Racial Preferences." Social Problems 58(2): 189-212. http://dx.doi .org/10.1525/ sp.2011.58.2.189.

Fitzpatrick, Joseph P. 1966. "The importance of community in the process of immigrant assimilation." International Migration Review 1:6-16. http://dx. doi .org/10. 2307/3002231.

Frank, Reanne, Ilana Redstone Akresh, and Bo Lu. 2010. “Latino Immigrants and the U.S. Racial Order: How and Where Do They Fit In?" American Sociological Review 75:378-401. http://dx.doi.org/10.1177/0003122410372216.

Golash-Boza, Tanya and William Darity. 2008. "Latino Racial Choices: The Effects of Skin Colour and Discrimination on Latinos' and Latina's Racial Self-Identifications." Ethnic $\mathcal{E}$ Racial Studies 31:899-934. http://dx . doi .org/10.1080/01419870701568858.

Gomez, Laura E. 2007. Manifest Destinies: The Making of the Mexican American Race. New York: New York University Press.

Hamill, Sean D. 2008. “Mexican's Death Bares a Town's Ethnic Tension." New York Times, August 5 .

Hitlin, Steven, J. Scott Brown, and Glen H. Elder, Jr. 2007. “Measuring Latinos: Racial Classification and Self-Understandings." Social Forces 86:: 587-611http://dx.doi.org/ $10.1093 / \mathrm{sf} / 86.2 .587$.

Huntington, Samuel P. 2004. Who Are We? The Challenges to America's National Identity. New York: Simon \& Schuster.

Iceland, John. 2009. Where We Live Now: Immigration and Race in the United States. Berkeley: University of California Press.

Jiménez, Tomás R. 2010. Replenished Ethnicity: Mexican Americans, Immigration, and Identity. Berkeley: University of California Press.

King, Ryan D., Steven F. Messner, and Robert D. Baller. 2009. “Contemporary Hate Crimes, Law Enforcement, and the Legacy of Racial Violence." American Sociological Review 74:291-315. http://dx.doi.org/10.1177/000312240907400207.

Kohut, Andrew and Roberto Suro. 2006. “America's Immigration Quandary: No Consensus on Immigration Problem or Proposed Fixes". Pew Research Center. Washington, D.C.

Kusow, Abdi. 2006. "Migration and Racial Formations among Somali Immigrants in North America." Journal of Ethnic E Migration Studies 32:533-551. http : //dx . doi . org/10 . 1080/ 13691830600555079.

Landale, Nancy S. and R. S. Oropesa. 2002. “White, Black, or Puerto Rican? Racial SelfIdentification among Mainland and Island Puerto Ricans." Social Forces 81:231-254. http://dx.doi.org/10.1353/sof.2002.0052. 
Logan, John R. and Brian J. Stults. 2011. "The Persistence of Segregation in the Metropolis: New Findings from the 2010 Census." US2010 Research Report, Brown University, http://www.s4.brown.edu/us2010/Data/Report/report2.pdf

Massey, Douglas S. and Magaly Sanchez R. 2010. Brokered Boundaries: Creating Immigrant Identity in Anti-Immigrant Times. New York: Russell Sage Foundation.

Michael, Joseph and Jeffrey M. Timberlake. 2008. "Are Latinos Becoming White? Determinants of Latinos' Racial Self-Identification in the U.S." Pp. 107-122 in Racism in Post-Race America: New Theories, New Directions, edited by C.A. Gallagher. Chapel Hill, NC: Social Forces.

Morning, Ann. 2008. "Ethnic Classification in Global Perspective: A Cross-National Survey of the 2000 Census Round." Population Research and Policy Review 27:239-272. http: //dx.doi.org/10.1007/s11113-007-9062-5.

Oboler, S. 1995. Ethnic labels, Latino lives: identity and the politics of (re)presentation in the United States. Minneapolis, University of Minnesota Press.

Office of Management and Budget. 1997. Revisions to the standards for the classification of Federal data on race and ethnicity. Federal Register 62FR58781-58790, October 30, 1997. http://www . whitehouse.gov/omb/fedreg/1997standards.html .

Oropesa, R.S., Nancy S. Landale, and Meredith J. Greif. 2008. "From Puerto Rican to PanEthnic in New York City." Ethnic and Racial Studies 31: 1315-1339. http://dx. doi .org/ 10.1080/01419870701722521.

Park, Robert E. and Ernest W. Burgess. 1925. The City. Chicago: University of Chicago Press.

Portes, Alejandro, and Ruben G. Rumbaut. 1990. Immigrant America: A Portrait. Berkeley: University of California Press.

Portes, Alejandro, and Ruben G. Rumbaut. 2001. Legacies: The Story of the Immigrant Second Generation. Berkeley: University of California Press.

Rodriguez, C. E. 2000. Changing Race: Latinos, the Census, and the History of Ethnicity in the United States. New York: New York University Press.

Rodriguez, C. E. and H. Cordero-Guzman. 1992. "Placing Race in Context." Ethnic and Racial Studies 15(4): 523-542. http://dx.doi.org/10.1080/01419870.1992.9993762.

Rodriguez, Gregory. 2007. Mongrels, Bastards, Orphans, and Vagabonds. New York: Pantheon Books.

Rumbaut, Ruben G. 2008. "Reaping What You Sew: Immigration, Youth, and Reactive Ethnicity." Applied Developmental Science 22:1-4.

Rumbaut, R. G. 2009. "Pigments of Our Imagination: On the Racialization and Racial Identities of 'Hispanics' and 'Latinos"'. Pp. 15-36 in How the U.S. Racializes Latinos: White Hegemony and Its Consequences, edited by J. A. Cobas, J. Duany and J. R. Feagin. London: Paradigm Publishers.

Saperstein, Aliya and Andrew M. Penner. 2012. "Racial Fluidity and Inequality in the United States." American Journal of Sociology 118: 676-727. http://dx. doi .org/10.1086/667722.

Saperstein, Aliya, Andrew M. Penner, and Ryan Light. 2013. "Racial Formation in Perspective: Connecting Individuals, Institutions and Power Relations." Annual Review of Sociology 39: 359-378. http://dx.doi.org/10.1146/annurev-soc-071312-145639.

Staiger, Douglas and James H. Stock. 1997. "Instrumental Variables Regression with Weak Instruments." Econometrica 65:557-586. http://dx.doi .org/10.2307/2171753.

Tafoya, Sonya M. 2005. "Shades of Belonging: Latinos and Racial Identity." Harvard Journal of Hispanic Policy 17:58-78. 
Telles, E. E. and V. Ortiz. 2008. Generations of Exclusion: Mexican Americans, Assimilation, and Race. New York: Russell Sage Foundation.

Tolnay, Stewart E., Glenn Deane, and E. M. Beck. 1996. “Vicarious Violence: Spatial Effects in Southern Lynching, 1890-1919." American Journal of Sociology 102:788-815. http: //dx.doi.org/10.1086/230997.

Vaquera, Elizabeth and Grace Kao. 2006. “The Implications of Choosing No-Race on the Salience of Hispanic Identity: How Racial and Ethnic Identification Intersect among Hispanic Adolescents." The Sociological Quarterly 47: 375-396. http://dx.doi.org/10. $1111 / j .1533-8525.2006 .00050 . x$.

Wimmer, Andreas. 2007. "How (Not) to Think about Ethnicity in Immigrant Societies." Oxford Centre on Migration, Policy and Society Working Paper Series 07-44:1-38.

Wimmer, Andreas. 2008. "The Making and Unmaking of Ethnic Boundaries: A Multilevel Process Theory." American Journal of Sociology 113:970-1022. http://dx.doi.org/10. $1086 / 522803$.

Yancey, George. 2003. Who is White? Latinos, Asians, and the New Black/Nonblack Divide. Boulder, CO: Lynne Rienner.

Yancey, William L., Eugene P. Ericksen, and Richard N. Juliani. 1976. “Emergent Ethnicity: A Review and Reformulation." American Sociological Review 41:391-403. http: //dx. doi . org/10.2307/2094249.

Acknowledgements: An earlier version of this paper was presented at the annual meeting for the Population Association of America in San Francisco in 2012. The authors thank Sal Oropesa for his helpful comments on an earlier draft of this paper. We also thank Andrew Raridon for his research assistance.

Michael T. Light: Department of Sociology, Purdue University.

E-mail: mlight@purdue.edu.

John Iceland: Department of Sociology and Criminology, Pennsylvania State University. E-mail: jdi10@psu.edu. 